\title{
Relação Entre Duração dos Eventos de El Niño com as Condições do Atlântico Tropical e a Precipitação no Ceará
}

\author{
Enzo Pinheiro ${ }^{1}$ iD , Francisco das Chagas Vasconcelos Júnior ${ }^{1}$, \\ Eduardo Sávio Passos Rodrigues Martins ${ }^{1}$, Diógenes Fontenele Passos ${ }^{1}$, \\ José Marcelo Rodrigues Pereira ${ }^{1}$ \\ ${ }^{1}$ Fundação Cearense de Meteorologia e Recursos Hídricos, Fortaleza, CE, Brasil.
}

Recebido em 3 de Fevereiro de 2017 - Aceito em 20 de Março de 2018

\begin{abstract}
Resumo
O artigo investiga como eventos de El Niño de diferentes durações afetam a circulação atmosférica no Atlântico Tropical Norte (ATN), quais consequências dessas alterações sobre a variabilidade interanual da temperatura da superfície do mar (TSM) na região e qual a resposta, em termos de anomalias de precipitação, sobre o Ceará. A análise foi feita através da composição de variáveis oceanográficas e atmosféricas para 18 eventos de El Niño, divididos em eventos de curta e longa duração. Os resultados mostram que os eventos de maior duração resultaram em anomalias positivas de TSM sobre a região do ATN, favorecendo, assim, ao desenvolvimento do gradiente inter-hemisférico de anomalias de TSM positivo e um regime de precipitação abaixo da média no Ceará. Por outro lado, as alterações na circulação atmosférica sobre o ATN não se mostraram tão intensas nos anos em que o El Niño apresentou menor duração, resultando em anomalias de TSM no ATN próximas a zero e consequentemente não foi observado um gradiente de anomalias de TSM no Atlântico Tropical. A composição das anomalias de precipitação sobre o Ceará próximas de zero nesses anos condiz com essa não formação de um gradiente de anomalias de TSM.
\end{abstract}

Palavras-chave: teleconexão, temperatura da superfície do mar, Ceará.

\section{Relations Among Duration of the El Niño Events, Tropical Atlantic Conditions and Rainfall Over Ceará}

\begin{abstract}
This paper investigates how El Niño events of different durations affect the atmospheric circulation over the Tropical North Atlantic (TNA) region, what are the consequences of these alterations in the sea surface temperature (SST) interannual variability and what are the responses, in terms of precipitation anomalies, over Ceará. Composite analyses of oceanographic and atmospheric variables were made for 18 El Niño years, divided between events of short and long duration. Events that lasted longer resulted in positive SST anomalies in the TNA region, leading to an interhemispheric gradient of SST anomalies in the Tropical Atlantic and below normal precipitation anomalies over Ceará. On the other hand, the alterations in the atmospheric circulation on TNA, during years of short duration El Niño, have not shown to be as intense as those in years of long duration El Niño. This resulted in SST anomalies on TNA close to zero and consequently, the interhemispheric gradient of SST anomalies was not observed. The near normal precipitation anomalies composites are consistent with the no formation of a SST anomalies gradient.
\end{abstract}

Keywords: teleconnection, sea surface temperature, Ceará.

\section{Introdução}

As temperaturas das águas superficiais do Atlântico Tropical determinam o posicionamento da Zona de Convergência Intertropical (ZCIT), o principal sistema responsável pelas chuvas no Ceará, o qual está localizado no Norte do Nordeste do Brasil. A ZCIT representa um cinturão de nuvens de convecção profunda, formadas pelo transporte, por parte dos ventos alísios, de massas de ar quentes e úmidas para altos níveis. Esta migra meridionalmente durante o ano seguindo o ciclo solar anual, alcançando sua

Autor de correspondência: Enzo Pinheiro, pinheiroenzo92@gmail.com. 
posição mais ao sul durante os meses de março e abril (Hastenrath e Heller, 1977; Hatenrath, 1984). Anos muito secos (chuvosos) no Ceará são consequência de um posicionamento anômalo mais ao norte (sul) da ZCIT durante o outono austral, causado por maiores (menores) anomalias de temperatura da superfície do mar (TSM) no ATN do que no ATS, caracterizando um gradiente inter-hemisférico de anomalias de TSM positivo (negativo) (Moura e Shukla, 1981; Nobre e Shukla, 1996).

As mudanças nas condições atmosféricas e oceânicas no Atlântico Tropical Norte (ATN) e Sul (ATS) associadas ao El Niño são resultados de diversas formas de influência do fenômeno como já verificada por vários estudos (Zebiak, 1993; Curtis e Hastenrath, 1995; Chiang e Sobel, 2002; Rodrigues, 2011), dentre elas estão as alterações causadas pelas teleconexões trópicos-extratrópicos. Trenberth et al. (1998) relataram os avanços no entendimento do El Niño e das mudanças na circulação atmosférica global causadas pelo fenômeno. A advecção de vorticidade absoluta por pela componente divergente do fluxo, resultante do aquecimento das águas do Pacífico central e leste, é uma importante fonte de ondas de Rossby nos subtrópicos, regiões estas preferenciais para formação e intensificação de ondas de Rossby estacionárias (Sardeshmukh e Hoskins, 1988). Essa forçante é maior durante o verão austral, quando o El Niño alcança seu pico.

Bjerknes (1969) notou um aprofundamento da baixa das Aleutas no Pacífico Norte durante o verão austral associado ao El Niño. Horel e Wallace (1981) mostraram que o aprofundamento da baixa das Aleutas é acompanhado por anomalias positivas de geopotencial em $700 \mathrm{hPa}$ sobre a porção oeste do Canada e anomalias negativas sobre o sudeste dos Estados Unidos, indicando que o padrão Pacific North-American (PNA), descrito anteriormente por Wallace e Gutzler (1981), é um padrão preferencial de ocorrência durante anos de ENOS.

Associado a este trem de ondas, Curtis e Hastenrath (1995) encontraram padrões de divergência em altos níveis sobre o flanco equatorial da Alta Subtropical do Atlântico Norte (ASAN) com consequente diminuição da subsidência sobre o centro de alta pressão, e resultando em anomalias negativas de pressão ao nível do mar sobre esta região. Assim, se estabelece um gradiente meridional de pressão entre o ATN e o ATS, com pressões anomalamente maiores sobre a parte sul. Com base em estudos observacionais, a formação deste gradiente contribui para que os ventos alísios do Hemisfério Sul cruzem o equador e se tornem de oeste, devido à deflexão causada pela força de Coriolis. Este fato favorece a desaceleração dos ventos oriundos do Hemisfério Norte (Hastenrath et al., 1987; Curtis e Hastenrath, 1995; Efield e Mayer, 1997). Como resultado o fluxo de calor latente sobre o ATN é reduzido com consequente anomalias positivas de TSM, enquanto no ATS acontece o oposto (Chang et al., 1997).
Trenberth et al. (1998) citam que o tempo de duração do El Niño tem um papel importante na propagação de energia para longe da fonte de calor. Corroborando com este estudo, as análises de Karoly (1983) e de Li e Nathan (1994) mostram que quanto menor a escala de tempo, mais ligada ao equador é a resposta. Lee et al. (2008), realizando experimentos de controle da duração do El Niño utilizando o modelo geral de circulação atmosférica, sugerem que eventos de El Niño moderados com duração posterior a março podem resultar no aquecimento do ATN nos meses seguintes. No entanto, neste estudo os autores não realizam análises no que concerne ao entendimento da dinâmica atmosférica e oceânica no ATN em resposta a esses eventos de El Niño de diferentes durações, deixando a lacuna de quais as diferenças na circulação atmosférica no ATN em casos de El Niño de curta e longa durações.

O presente estudo se propõe a avançar no entendimento da influência do El Niño sobre o ATN através da ponte atmosférica, proposta inicialmente por Hastenrath (2000), com o foco no preenchimento de algumas lacunas, além da compreensão da influência destes padrões na precipitação do Norte do Nordeste durante a estação chuvosa da região. Assim, o presente estudo tem como objetivos identificar: (1) como a circulação atmosférica no ATN é afetada, considerando as diferenças nos padrões de aquecimento durante o verão austral no Pacífico equatorial, em anos de El Niño de curta e longa duração; (2) a resposta na anomalia de TSM no Atlântico Tropical durante o outono austral associado a essas possíveis mudanças na circulação atmosférica; (3) e por último, observar quais são os impactos causados no regime de precipitação no Ceará em anos de El Niño curto e longo.

A seção 2 do trabalho aborda a metodologia empregada, a qual inclui a descrição dos dados utilizados, a classificação da duração dos eventos de El Niño, a elaboração das composições e o cálculo da significância estatística. A seção 3 apresenta os resultados encontrados a partir da análise das composições e discussão com outros trabalhos que abordam o tema. Por último a seção 4 apresenta as conclusões deste trabalho.

\section{Materiais e Métodos}

Foram utilizadas médias mensais de TSM oriundas do Extended Reconstructed Sea Surface Temperature Version 4 (Haung et al., 2015; Liu et al., 2015) disponibilizadas pela National Oceanic and Atmospheric Administration (NOAA). Dados médios mensais das componentes zonal e meridional da velocidade do vento, altura geopotencial e ômega foram obtidos do NCEP/NCAR 40-years reanalysis (Kalnay et al., 1996). O período selecionado para análise foi de 1950 - 2013 (inclui-se aqui o período chuvoso de 2014).

Os dados dos acumulados mensais de precipitação do Ceará foram obtidos da rede pluviométrica da Fundação Cearense de Meteorologia e Recursos Hídricos. O período 
selecionado para os dados de precipitação foi igual ao período selecionado para TSM.

O método de seleção do El Niño utilizado foi o proposto por Trenberth (1997) com algumas adaptações. Para um ano ser caracterizado como ano de El Niño é necessário que as médias trimestrais do Oceânic Niño Index (definido como a média móvel de três meses de anomalias de TSM na região do Niño 3.4), a partir de setembro (setembro - novembro, outubro - dezembro, novembro - janeiro, dezembro - fevereiro) tenham valores acima de $0.5{ }^{\circ} \mathrm{C}$. Neste trabalho, qualquer referência a meses no ano de formação do El Niño será identificada pelo sufixo (0), enquanto os meses no ano de decaimento, após o pico do El Niño, é denotado com o sufixo $(+1)$.

Os eventos selecionados são então divididos de acordo com a sua duração. Anos nos quais o valor do índice Niño 3.4 for menor do que $0.5^{\circ} \mathrm{C}$ em março+1, são classificados como anos de El Niño curto (ShortEN); anos em que o valor do índice se mantiver $0.5^{\circ} \mathrm{C}$ ou acima no mês de março+1, são classificados como eventos de longa duração (LongEN).

Esta classificação é adotada pois desta forma se pode comparar o impacto do El Niño enquanto este permanece configurado e no caso em que o fenômeno já foi dissipado durante o início da estação chuvosa $(\operatorname{março+1)}$ no Estado do Ceará.

São feitas composições bimestrais e sazonais de anomalias de TSM para os eventos de curta e longa duração. Para as anomalias de altura geopotencial, velocidade do vento, ômega, PNM, divergência dos ventos e precipitação foram utilizadas composições bimestrais. A significância estatística das composições foi calculada utilizando a distribuição t de Student bicaudal (Wilks, 2008) ao nível de confiança de $95 \%$ e com $n-1$ graus de liberdade, onde $n$ representa o número de anos para cada caso analisado. Somente os valores absolutos das composições maiores do que $t_{\alpha(n-1)} S / \sqrt{(n-1)}$ são considerados estatisticamente significantes, onde $t_{\alpha(n-1)}$ representa o valor crítico (limiar de rejeição da hipótese nula para o nível de confiança escolhido) na distribuição t, para $\mathrm{n}-1$ graus de liberdade, e $\mathrm{S}$ é o desvio padrão da composição.

\section{Resultados e Discussões}

Dos 64 anos analisados na série do índice do Niño 3.4 entre os anos de 1950 e 2013, 18 deles se enquadraram na classificação de El Niño, sendo, conforme definições anteriores, 9 El Niños de curta duração e 9 de longa duração conforme mostrado na Tabela 1.

Na Fig. 1 é possível observar a distribuição dos índices Niño 1+2 e Niño 3.4 para cada um dos eventos de El Niño. Maior parte dos eventos que apresentaram curta duração também apresentaram anomalias de TSM na região do Niño $1+2$ menores do que $0.5{ }^{\circ} \mathrm{C}$, concentrando assim a maior parte do aquecimento anômalo na região do
Tabela 1 - Classificação dos anos de El Niño de acordo com a duração.

\begin{tabular}{llll}
\hline $\begin{array}{l}\text { Eventos de El Niño } \\
\text { de curta duração }\end{array}$ & $1953-1954$ & $1963-1964$ & $1969-1970$ \\
& $1976-1977$ & $1977-1978$ & $1987-1988$ \\
& $1994-1995$ & $2002-2003$ & $2006-2007$ \\
$\begin{array}{l}\text { Eventos de El Niño } \\
\text { de longa duração }\end{array}$ & $1957-1958$ & $1965-1966$ & $1972-1973$ \\
& $1982-1983$ & $1986-1987$ & $1991-1992$ \\
& $1997-1998$ & $2004-2005$ & $2009-2010$ \\
\hline
\end{tabular}

Niño 3.4. Em anos de El Niño de longa duração, as maiores anomalias de TSM também são na região do Niño 3.4, no entanto, com exceção de 2 eventos, a região do Niño 1+2 apresentou anomalias superiores a $0.5^{\circ} \mathrm{C}$, indicando que $\mathrm{o}$ aquecimento anômalo se estendeu pelo Pacífico central e leste.

A distribuição espacial das anomalias de TSM em DJF no Oceano Pacífico pode ser observada na Fig. 2. As configurações espaciais e magnitude das anomalias de TSM das composições de El Niños curtos e El Niños longos tem semelhança com as composições de El Niños na região da piscina quente (WP El Niño) e El Niños na região da língua fria (CT El Niño) respectivamente, mostradas no trabalho de Kug et al. (2008). Nesse artigo, os autores mostraram que os eventos de WP El Niño não têm uma duração tão grande quanto os eventos do CT El Niño, tendo em vista que nas composições do WP El Niño as anomalias de TSM no Pacífico equatorial em MAM já são praticamente inexistentes. Corroborando com esse fato, Zheng et al. (2014) concluem que nos El Niños centrais (comparável aos El Niños curtos no presente artigo e aos eventos de WP El Niño no estudo de Kug et al. (2008)) a região de máxima precipitação, responsável pelo aquecimento diabático da troposfera, coincide com a região de máxima cobertura de nuvens, responsável por um resfriamento diabático, ambas no Pacífico central. No caso dos El Niños costeiros, refe-

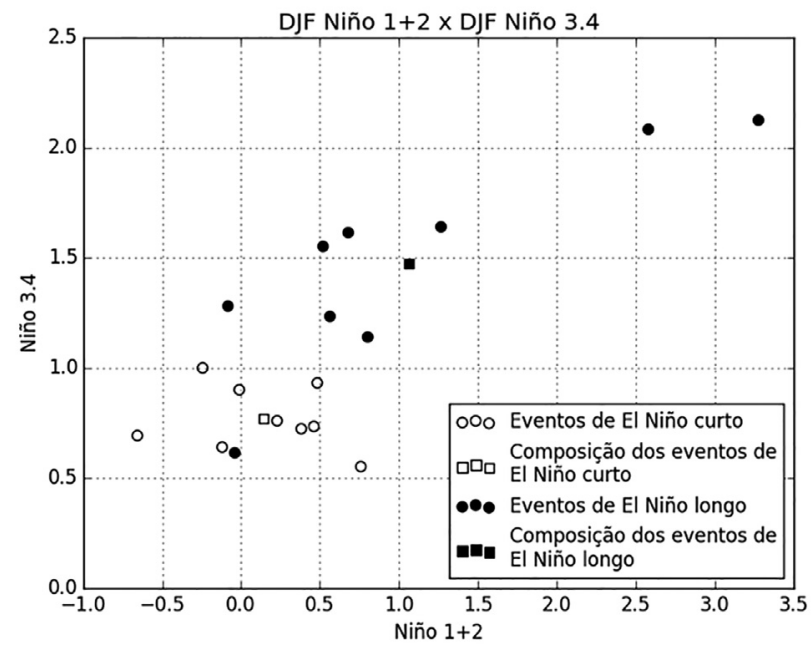

Figura 1 - Niño 1+2 x Niño 3.4 em DJF para os eventos de El Niño curto e eventos de El Niño longo. 

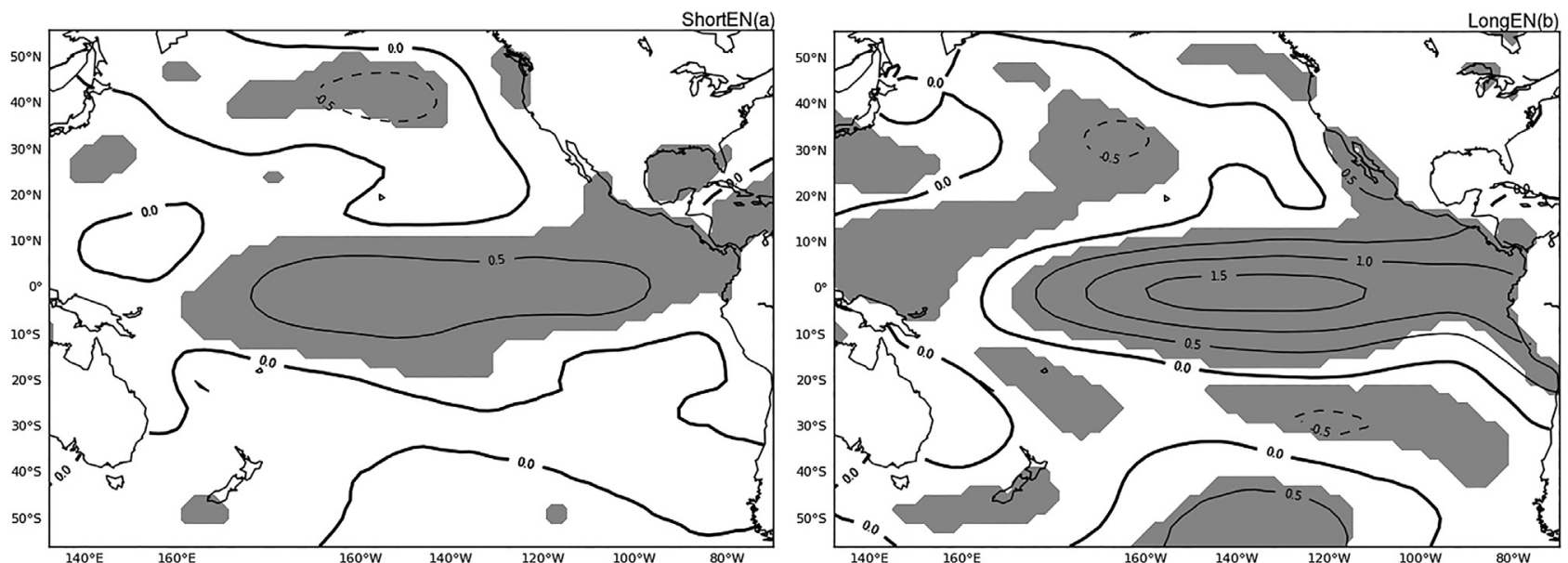

Figura 2 - Distribuição espacial das anomalias de TSM $\left(\mathrm{em}^{\circ} \mathrm{C}\right)$ em DJF das composições dos a) anos de El Niño curto e dos b) anos de El Niño longo com o espaçamento das isolinhas de $0,5^{\circ} \mathrm{C}$. Áreas em cinza são estatisticamente significantes ao nível de confiança de $95 \%$.

rentes ao El Niños longos neste trabalho e aos CT El Niño no trabalho de Kug et al. (2008), a região de máxima cobertura de nuvens também se localiza no Pacífico central, no entanto a região aquecimento diabático ocorrem por uma banda zonal extensa que abrange o Pacífico central até o Pacífico leste, e desta forma não é tão fortemente cancelado pelo resfriamento radiativo causado pela cobertura de nuvens. Assim, o feedback termodinâmico negativo produ-

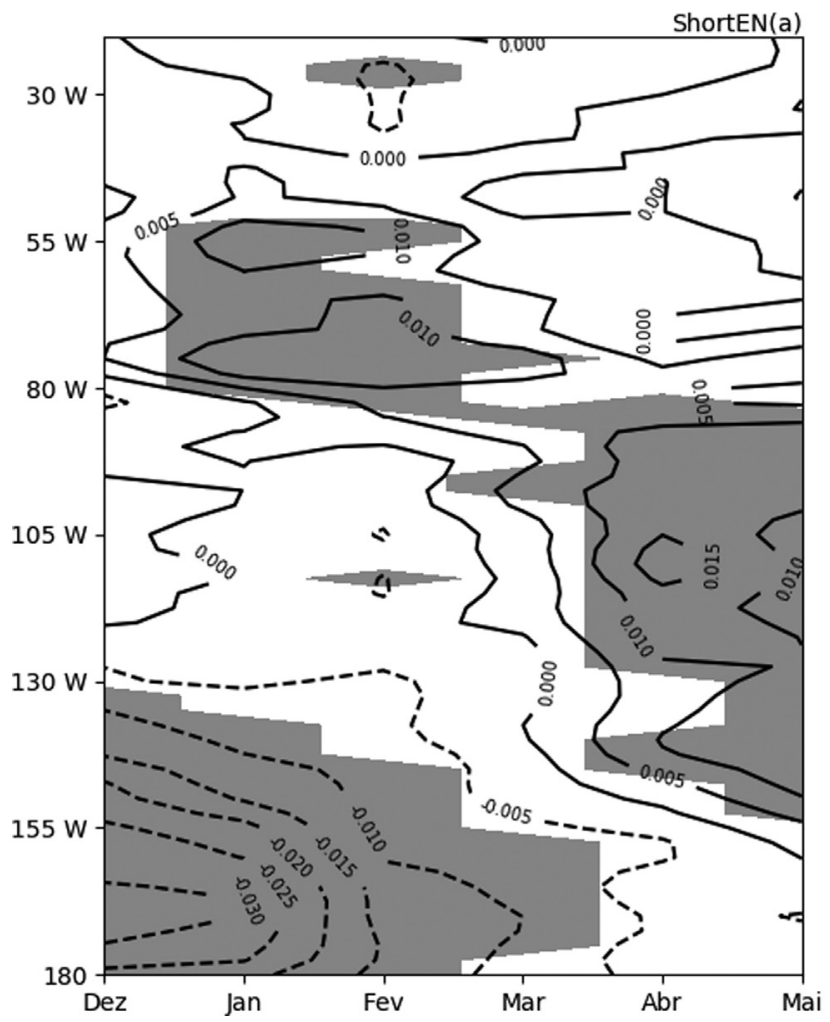

zido pelo efeito da cobertura de nuvens enfraquece fortemente o feedback de Bjerkness nos El Niños centrais, mas não totalmente para os El Niños costeiros, fazendo com que a duração dos El Niños centrais seja menor.

As Figs. 3a e 3b mostram a seção longitudinal da composição de ômega sobre o Pacífico equatorial e sobre o Atlântico equatorial para cada uma das categorias de El Niño. Na composição de El Niño curtos as anomalias de

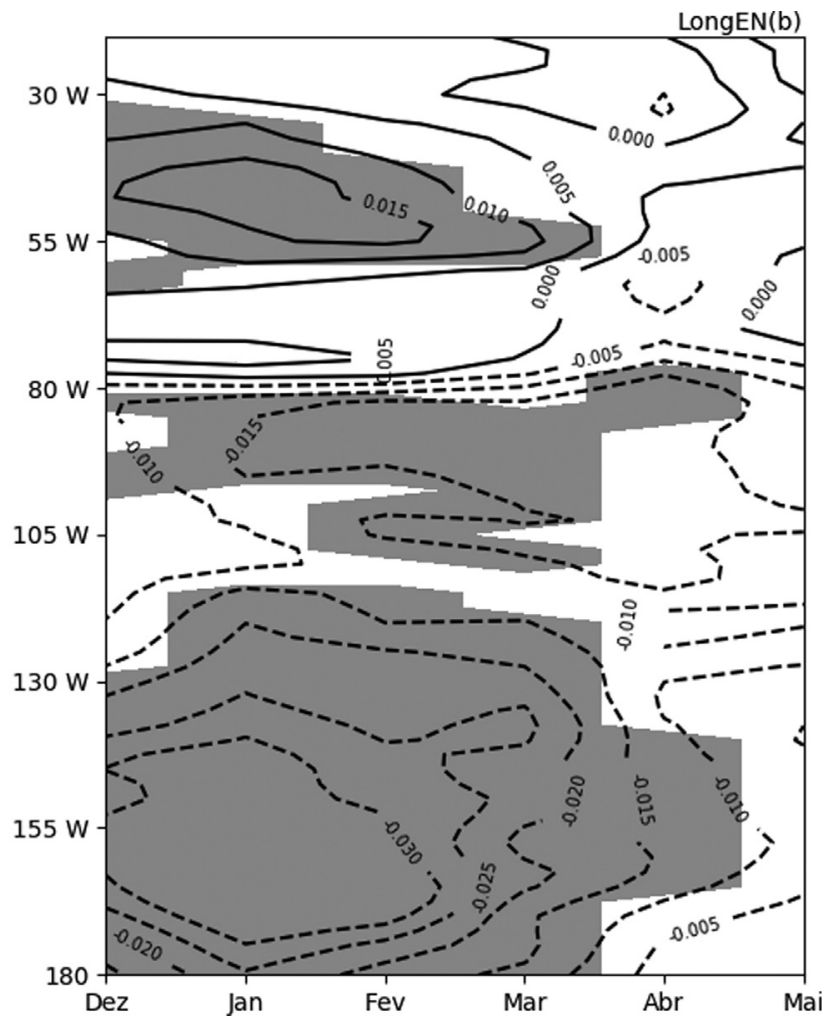

Figura 3 - Seção longitudinal (média entre $5^{\circ} \mathrm{N}$ e $5^{\circ} \mathrm{S}$ ) da composição de ômega em $500 \mathrm{hPa}$ sobre o Pacífico e Atlântico equatorial a) para anos de El Niño curto e b) anos de El Niño longo com o espaçamento das isolinhas de $5 \times 10^{-3} \mathrm{~Pa} / \mathrm{s}$. Áreas em cinza são estatisticamente significantes ao nível de confiança de $95 \%$. 
ômega negativas sobre o Pacífico, que representam a intensificação dos movimentos ascendentes sobre essa região, ficam restritas ao Pacífico central $\left(180^{\circ}-130^{\circ} \mathrm{W}\right)$, enquanto nos eventos de El Niño longos essas anomalias se estendem até a costa da América do Sul $\left(180^{\circ}-80^{\circ} \mathrm{W}\right)$. Resultados muito similares também foram obtidos por Kug et al. (2008). Em consequência disso, há uma defasagem longitudinal na região de anomalias positivas sobre o Atlântico equatorial entre dezembro e fevereiro, tendo em vista que em anos de El Niño curtos a subsidência anômala se concentra na região amazônica $\left(80-55^{\circ} \mathrm{O}\right)$ e nos eventos longos essas anomalias são observadas principalmente sobre o Nordeste do país $\left(55^{\circ}-30^{\circ} \mathrm{O}\right)$. Entre março e maio não são observadas anomalias significativas sobre o Atlântico equatorial, indicando que esses padrões de movimentos verticais não estão ligados à duração do evento e sim a posição de máxima anomalia de TSM.

Anomalias de divergência do vento em $200 \mathrm{hPa}$ (Figs. 4a e 4b) com intensidade maior sobre a região do Pacífico equatorial podem ser observadas na composição de anos de El Niño longo em comparação aos anos em que o fenômeno apresentou menor duração. Maiores anomalias no componente divergente do fluxo resultam em uma forçante maior para formação de ondas de Rossby na atmosfera como demonstrado por Sardeshmukh e Hoskins (1988) e Hoskins e Ambrizzi (1993).

Esta resposta pode ser observada na composição de anomalias de altura geopotencial em $200 \mathrm{hPa}$ (Figs. 5a e 5b). Embora em ambos os cenários haja a intensificação dos centros de alta e baixa pressões, especialmente no hemisfério norte, este padrão é mais claro nos anos de El Niño longo, em que os centros de sinais alternados se estendem do Pacífico equatorial ao Atlântico Norte. Condição condizente, como já mencionado, com maiores forçantes de ondas de Rossby (Rasmusson e Mo, 1993).

No final do verão austral a composição dos eventos de El Niño curto (Fig. 6a) mostra uma forte redução das anomalias de altura geopotencial, resultando no enfraquecimento do padrão PNA, enquanto em anos de El Niño longo (Fig. 6b) as anomalias continuam intensas, mantendo assim a forte influência sobre as latitudes extratropicais no HN.
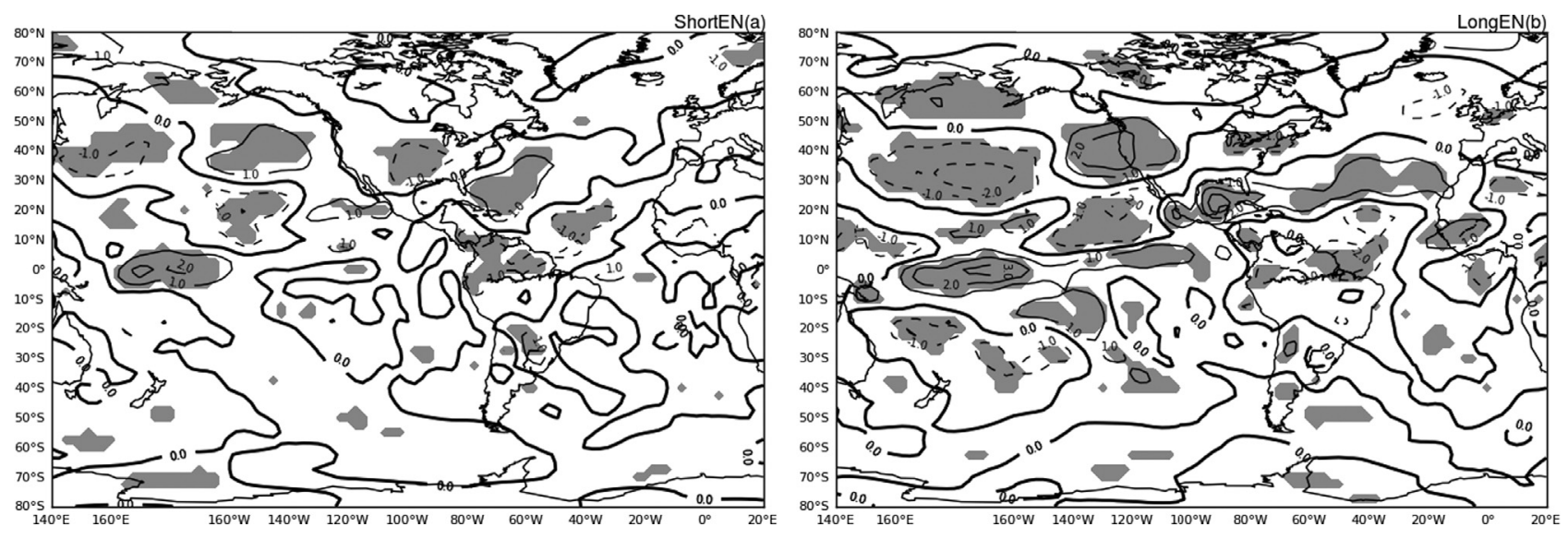

Figura 4 - Média bimestral (jan-fev) das anomalias de divergência em $200 \mathrm{hPa}$ a) para anos de El Niño curto e b) anos de El Niño longo com o espaçamento das isolinhas de $1 \times 10^{-6} \mathrm{~s}^{-1}$. Áreas em cinza são estatisticamente significantes ao nível de confiança de $95 \%$.
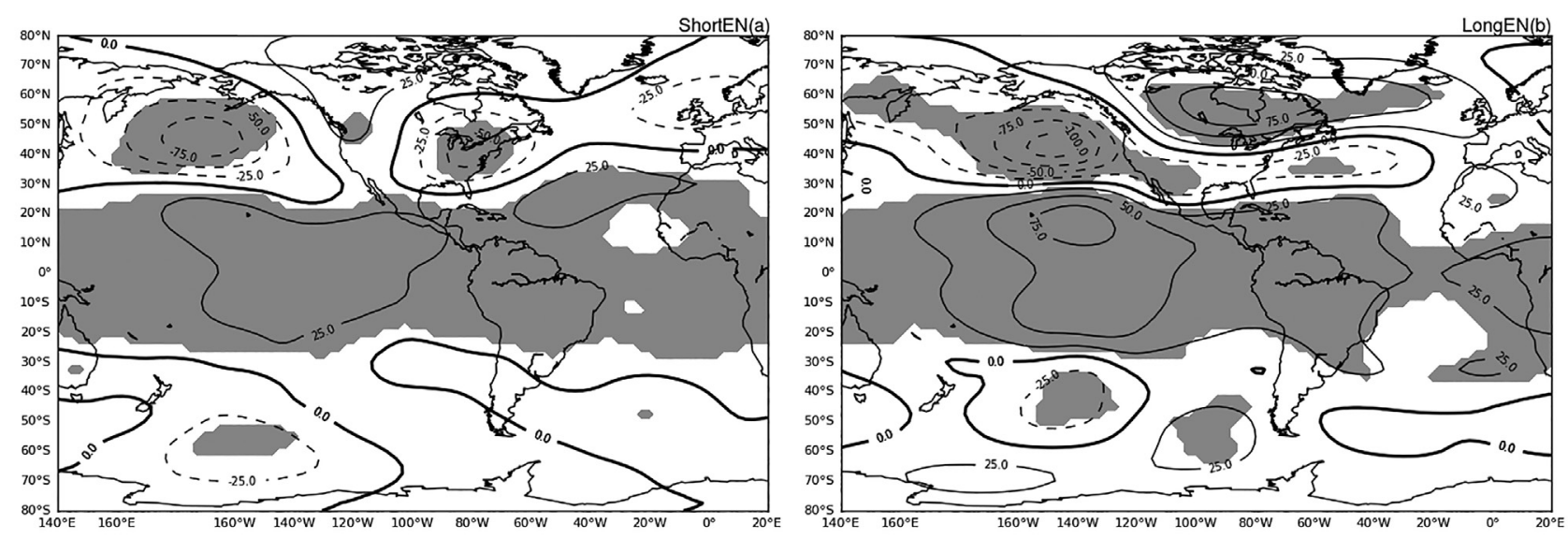

Figura 5 - Média bimestral (jan-fev) das anomalias de altura geopotenciao em $200 \mathrm{hPa}$ a) para anos de El Niño curto e b) para anos de El Niño longo com espaçamento das isolinhas de $25 \mathrm{mgp}$. Áreas em cinza são estatisticamente significantes ao nível de confiança de 95\%. 

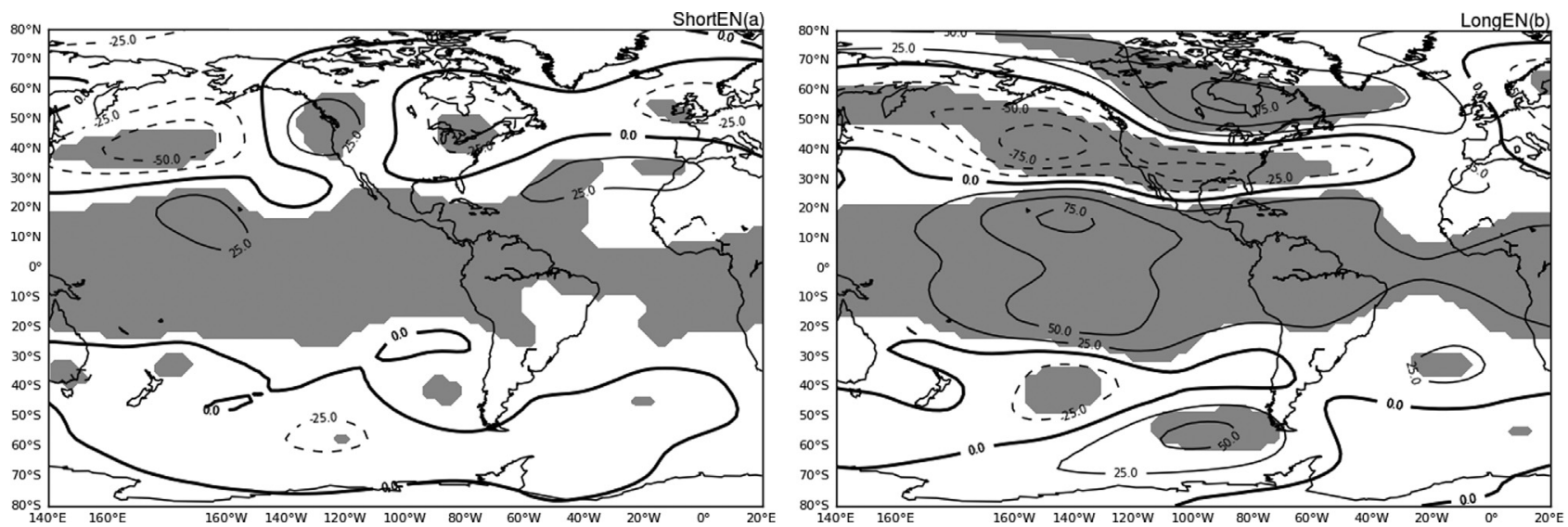

Figura 6 - Média bimestral (fev-mar) das anomalias de altura geopotenciao em $200 \mathrm{hPa}$ a) para anos de El Niño curto e b) para anos de El Niño longo com espaçamento das isolinhas de 25 mgp. Áreas em cinza são estatisticamente significantes ao nível de confiança de 95\%.

Associado a isso, diferentes respostas podem ser observadas sobre a região do ATN durante o final do verão austral. Em anos de El Niño longo as repostas atmosféricas sobre o Atlântico Tropical são condizentes com o que foi demonstrado anteriormente (Curtis e Hastenrath, 1995; Enfield e Mayer, 1997). Anomalias positivas de divergência em $200 \mathrm{hPa}$ podem ser observadas sobre a região da ASAN (Fig. 7b), com consequente menor movimento vertical subsidente sobre o centro de alta pressão (Fig. 8b). Isso reduz a pressão superficial sobre o ATN (Fig. 9b), formando um gradiente de pressão norte-sul sobre o Atlântico Tropical, favorecendo os alísios do Atlântico Sul a cruzarem o equador e desacelerarem os alísios do Atlântico Norte como observado na Fig. 10b, onde é visível fortes anomalias de vento na direção sudeste no HS enquanto no $\mathrm{HN}$ as anomalias na direção sudoeste são predominantes na região do ATN. Consequentemente há um enfraquecimento no feedback entre vento, evaporação e TSM (WES feedback), diminuindo o fluxo de calor latente sobre o ATN (Fig. 11b) (Chang et al., 1997).

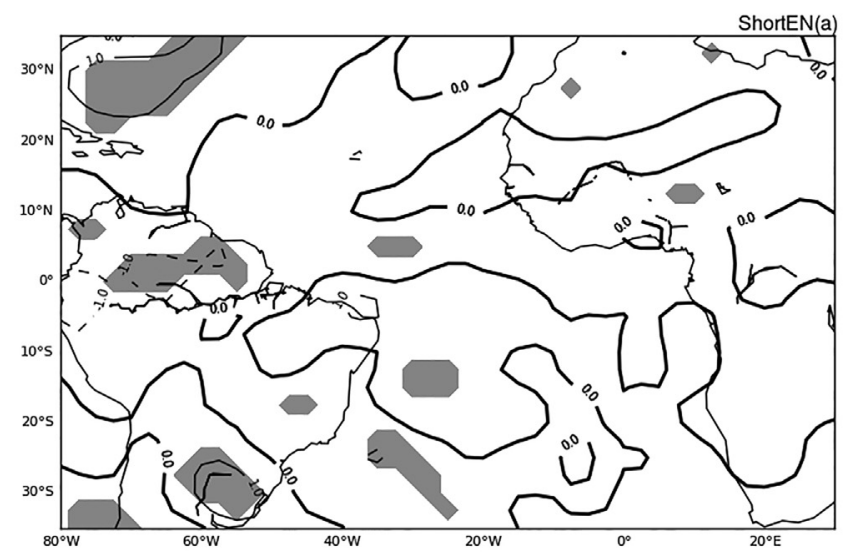

Já em anos de El Niño curto as respostas atmosféricas são diferentes. Anomalias de divergência (Fig. 7a) apresentam menor intensidade com associado maiores anomalias do ômega sobre a região da ASAN (Fig. 8a) quando comparados aos eventos de El Niño longo. A composição da PNM mostra que aproximadamente toda a região do Atlântico Tropical apresenta condições próximas da neutralidade (Fig. 9a). Condizente com isso são observadas fracas anomalias de vento em superfície, indicando que não há formação de um gradiente inter-hemisférico de pressão, mantendo os ventos alísios com condições também próximas da normalidade na região do Atlântico Tropical (Fig. 10a). Desta forma, o WES feedback se mantem praticamente inalterado, consequentemente há poucas alterações no fluxo de calor latente (Fig. 11a) no ATN.

As composições de março e abril das anomalias de TSM (Fig. 12) mostram os resultados das alterações no WES feedback. Fracas anomalias de TSM na maior parte da região do Atlântico Tropical são observadas posteriores a eventos de El Niño curto, enquanto, no outono austral que sucede os eventos de El Niño longo, anomalias positivas

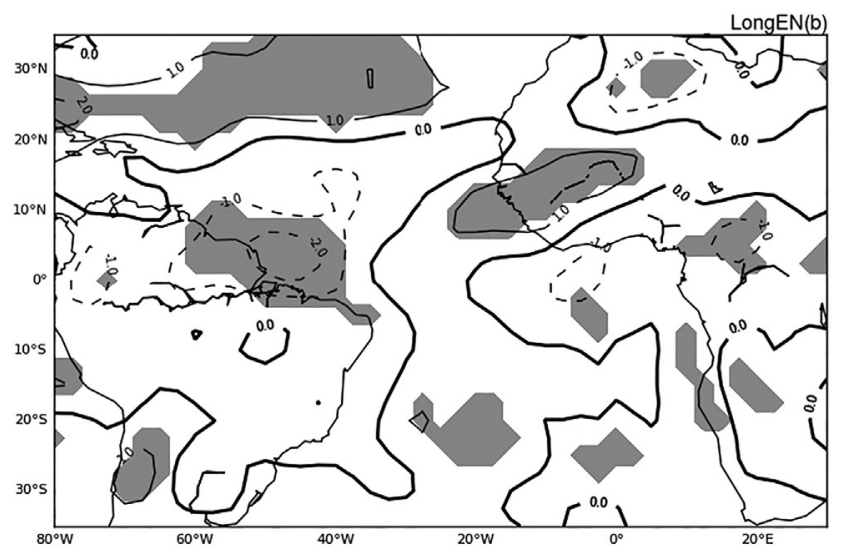

Figura 7 - Média bimestral (fev-mar) das anomalias de a) divergência em 200 hPa para anos de El Niño curto e b) anos de El Niño longo com o espaçamento das isolinhas de $1 \times 10^{-6} \mathrm{~s}^{-1}$. Áreas em cinza são estatisticamente significantes ao nível de confiança de $95 \%$. 

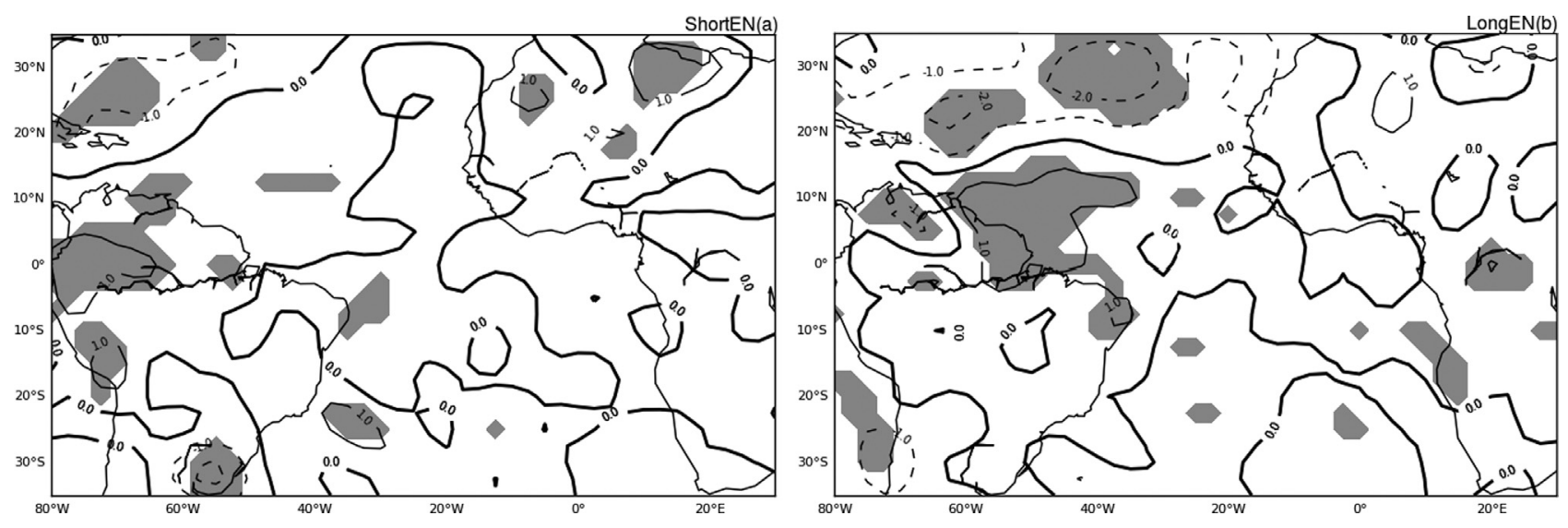

Figura 8 - Média bimestral (fev-mar) das anomalias de a) ômega em 500 hPa para anos de El Niño curto e b) anos de El Niño longo com o espaçamento das isolinhas de $1 \times 10^{-3} \mathrm{~Pa} / \mathrm{s}$. Áreas em cinza são estatisticamente significantes ao nível de confiança de $95 \%$.
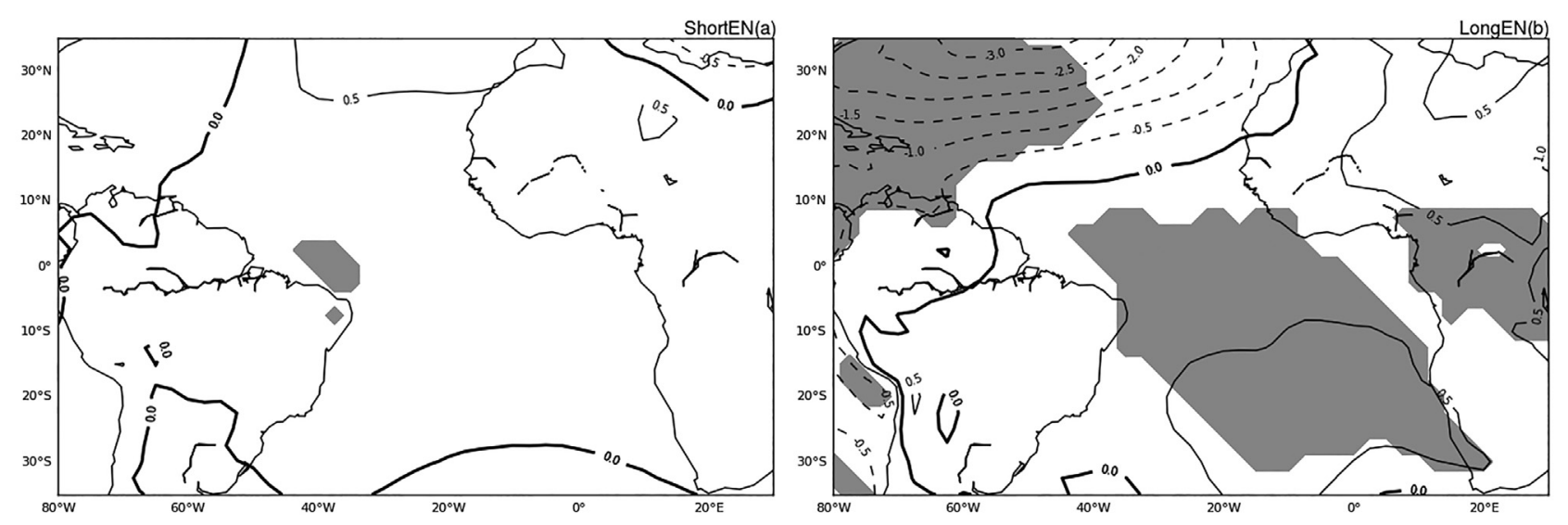

Figura 9 - Média bimestral (fev-mar) das anomalias de a) PNM para anos de El Niño curto e b) anos de El Niño longo com o espaçamento das isolinhas de $0,5 \mathrm{hPa}$. Áreas em cinza são estatisticamente significantes ao nível de confiança de $95 \%$.
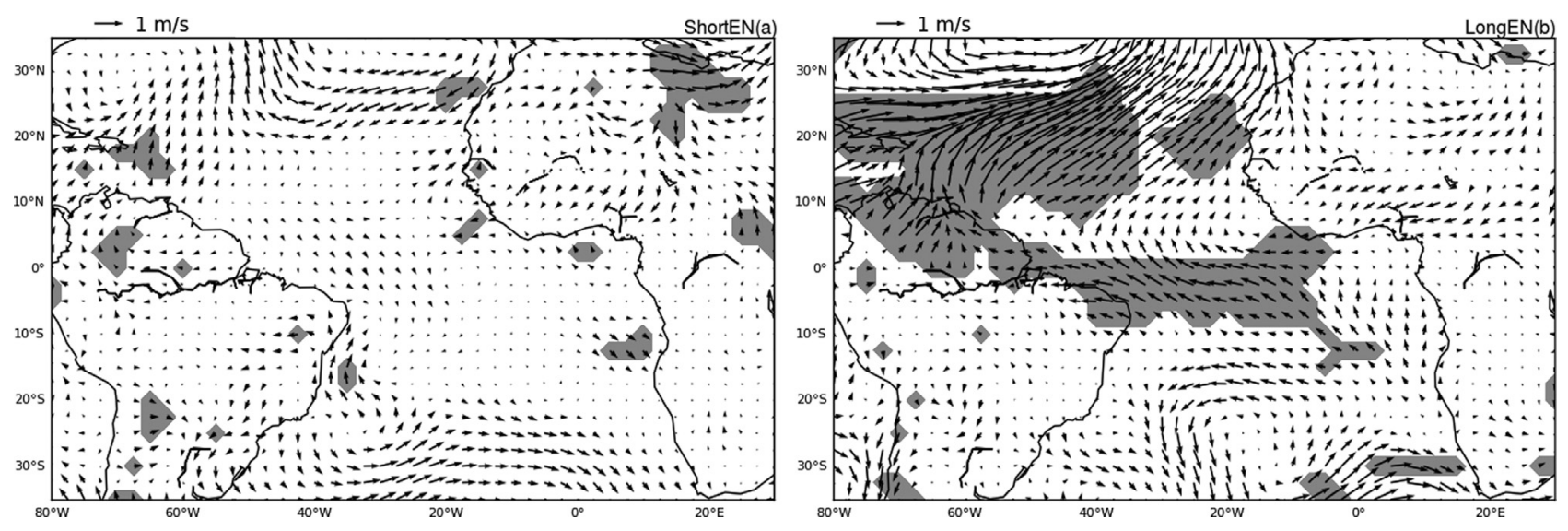

Figura 10 - Média bimestral (fev-mar) das anomalias de a) Vento em $1000 \mathrm{hPa}$ para anos de El Niño curto e b) anos de El Niño longo com vetores em m/s. Áreas em cinza são estatisticamente significantes ao nível de confiança de 95\%.

predominam sobre o ATN e anomalias em torno de zero são visíveis na maior parte do ATS com exceção da região próximas a costa da África onde são observadas anomalias negativas de TSM.
Dos nove eventos de El Niño longo, oito foram sucedidos por um gradiente inter-hemisférico de anomalias de TSM positivo no Atlântico Tropical (Fig. 13a). A média dos gradientes ficou em torno de $0.5^{\circ} \mathrm{C}$, com 
uma visível tendência de aumento dos mesmos com a proximidade do outono austral. Em anos de El Niño curto o gradiente médio ficou em torno de $0.1^{\circ} \mathrm{C}$ para o mesmo período, com somente três, dos nove eventos, resultando
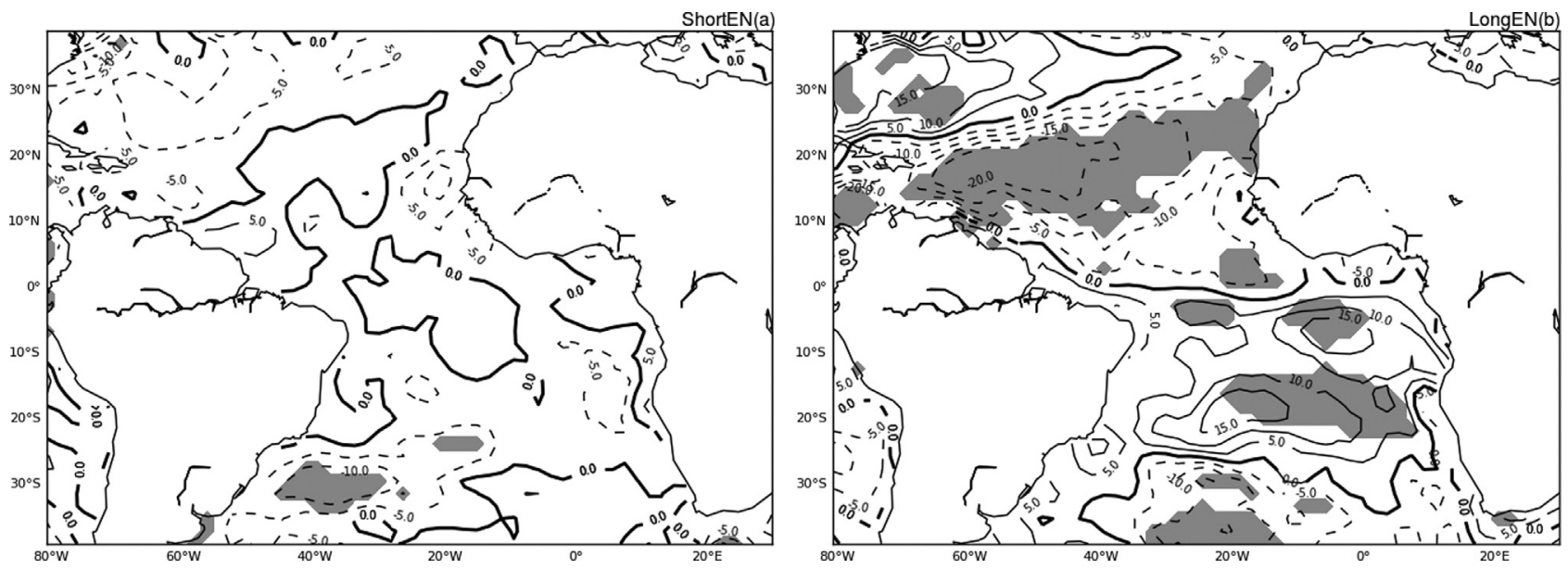

Figura 11 - Média bimestral (fev-mar) das anomalias de a) Fluxo de calor latente em superfície para anos de El Niño curto e b) anos de El Niño longo com o espaçamento das isolinhas de $5 \mathrm{~W} / \mathrm{m}^{2}$. Áreas em cinza são estatisticamente significantes ao nível de confiança de $95 \%$.
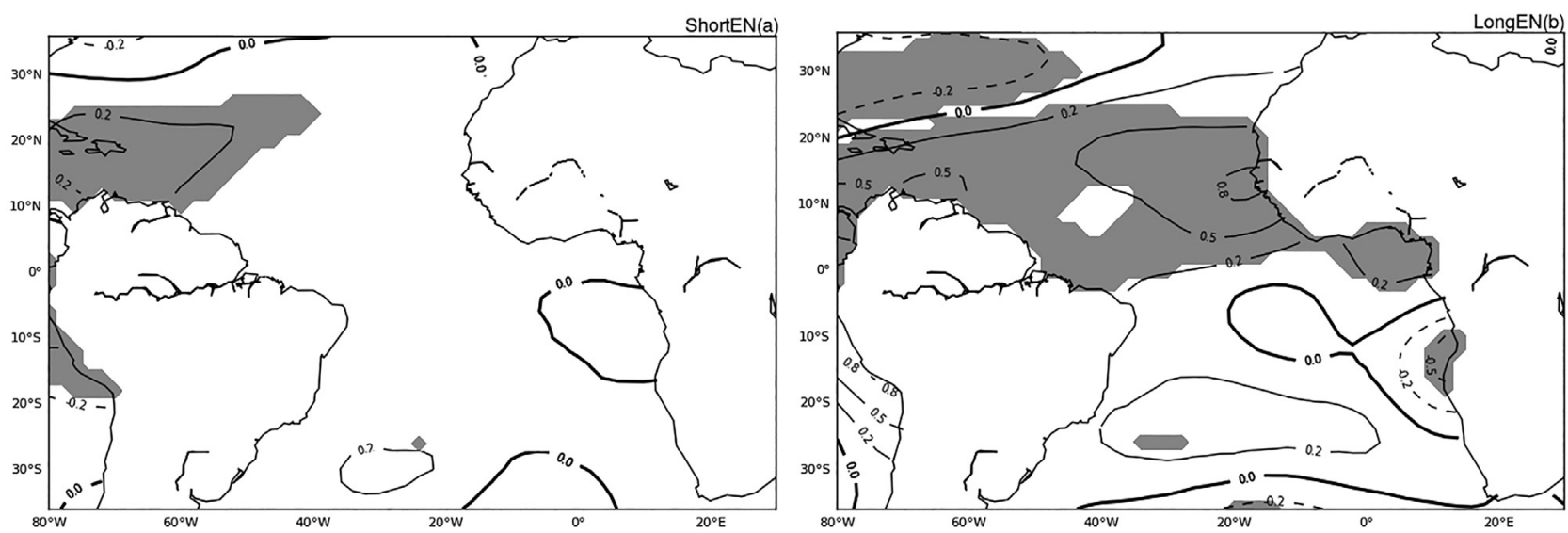

Figura 12 - Composição bimestral (março - abril) das anomalias de TSM no Atlântico Tropical para a) anos de El Niño curto e b) para anos de El Niño longo com o espaçamento das isolinhas de $0,3{ }^{\circ} \mathrm{C}$. Áreas em cinza são estatisticamente significantes ao nível de confiança de $95 \%$.
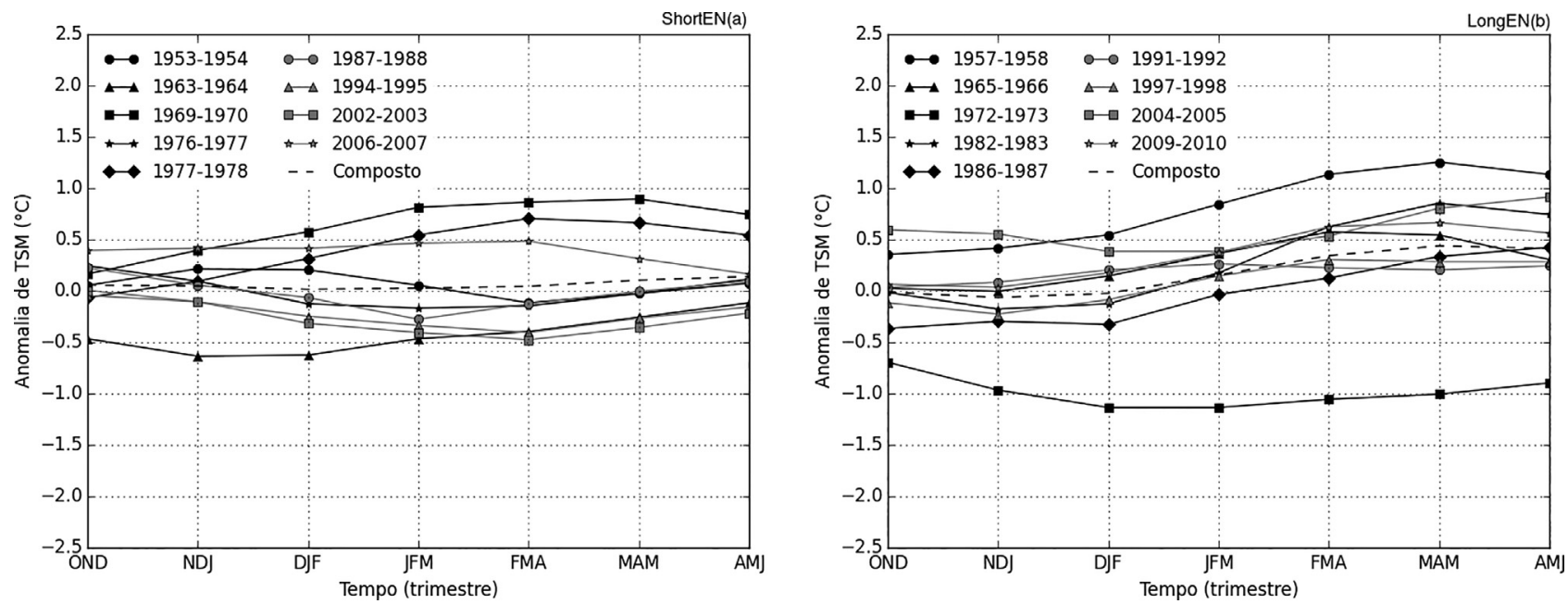

Figura 13 - Série temporal do gradiente inter-hemisférico de anomalias de TSM do Atlântico Tropical dos a) anos de El Niño curto e b) dos anos de El Niño longo. 
em um gradiente positivo (Fig. 13b) durante o mesmo período.

As alterações no ramo ascendente da circulação de Hadley no Atlântico (Fig. 14), observadas na composição da seção latitudinal das anomalias de ômega, confirmam esses padrões observados nos gradientes. Fica claro que em anos de El Niños longos há uma diminuição dos movimentos ascendentes sobre o ATS entre março e maio, enquanto no ATN há um fortalecimento do ramo ascendente da célula de Hadley. Já a composição de El Niño curtos, além de mostrar o padrão oposto dos eventos longos, com anomalias negativas sobre o ATS e positivas sobre o ATN, as magnitudes das anomalias são pequenas, indicando que há poucas alterações na célula meridional.

Anos de precipitação abaixo da média no Ceará são anos em que a ZCIT se mantém em latitudes acima de sua posição climatológica durante a maior parte do período chuvoso. Desta forma, dos nove eventos de El Niño longo, sete deles foram sucedidos por anos de precipitação abaixo da média (os anos 1958, 1973, 1983, 1992, 1998, 2005, 2010) e dois acima de média (os anos de 1966, 1987) (Fig. 15b). Da totalidade de eventos, aproximadamente $80 \%$ deles apresentaram anomalias negativas do acumulado de precipitação de março e abril (MA) (Fig. 16b).

Por outro lado, em anos de El Niño curto (Figs. 15a e 16a), dos nove eventos, quatro, ou aproximadamente $44 \%$ do total, resultaram em anomalias do acumulado bimestral

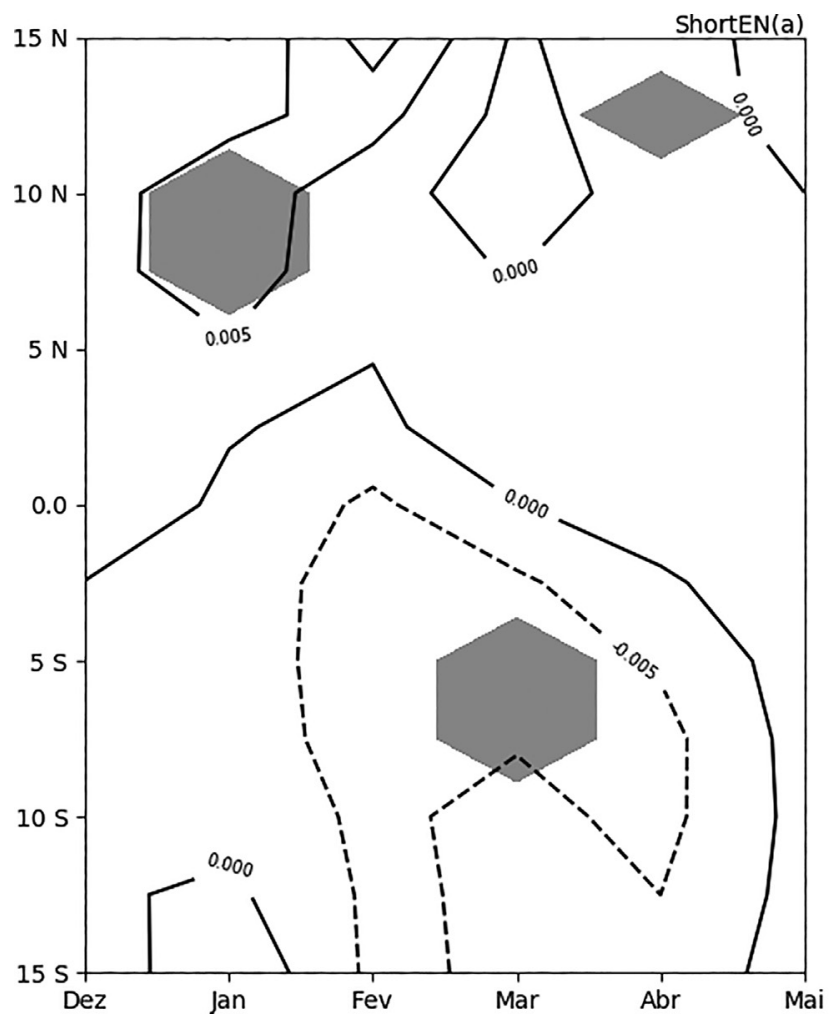

abaixo da média (os anos 1954, 1970, 1978 e 2007) e cinco, ou aproximadamente $56 \%$ do total de eventos, acima da média (os anos 1964, 1977, 1988, 1995 e 2003).

Levando em conta que a média climatológica do acumulado de MA é aproximadamente $387 \mathrm{~mm}$, quatro dos nove eventos longos resultaram em anomalias entre $40 \% \mathrm{e}$ $80 \%$ menores do que a média (Fig. 16b), enquanto em anos de El Niño curto, o máximo registrado foram anomalias até $40 \%$ menores do que a média de MA (Fig. 16a). As composições das anomalias de precipitação acumulada para o bimestre MA foram aproximadamente $-110 \mathrm{~mm}$ e $0 \mathrm{~mm}$ respectivamente (Fig. 15). Desta forma, além da maior probabilidade de ocorrência de eventos de seca em anos de El Niño longo, a severidade da seca meteorológica também tende a ser maior após esses eventos.

\section{Conclusões}

Em anos de El Niño curto, os centros de pressões característicos do padrão PNA se mostram bastante enfraquecidos no final do verão e início do outono austral, diferente do que ocorre em anos de El Niño longo, no qual o padrão se mantem intenso e atuante sobre as latitudes extratropicais. Isso pode ser observado na resposta atmosférica sobre a região do Oceano Atlântico, no qual a cadeia de mecanismos que relaciona o PNA em anos de El Niño à precipitação no Nordeste, proposta por Curtis e Hastenrath

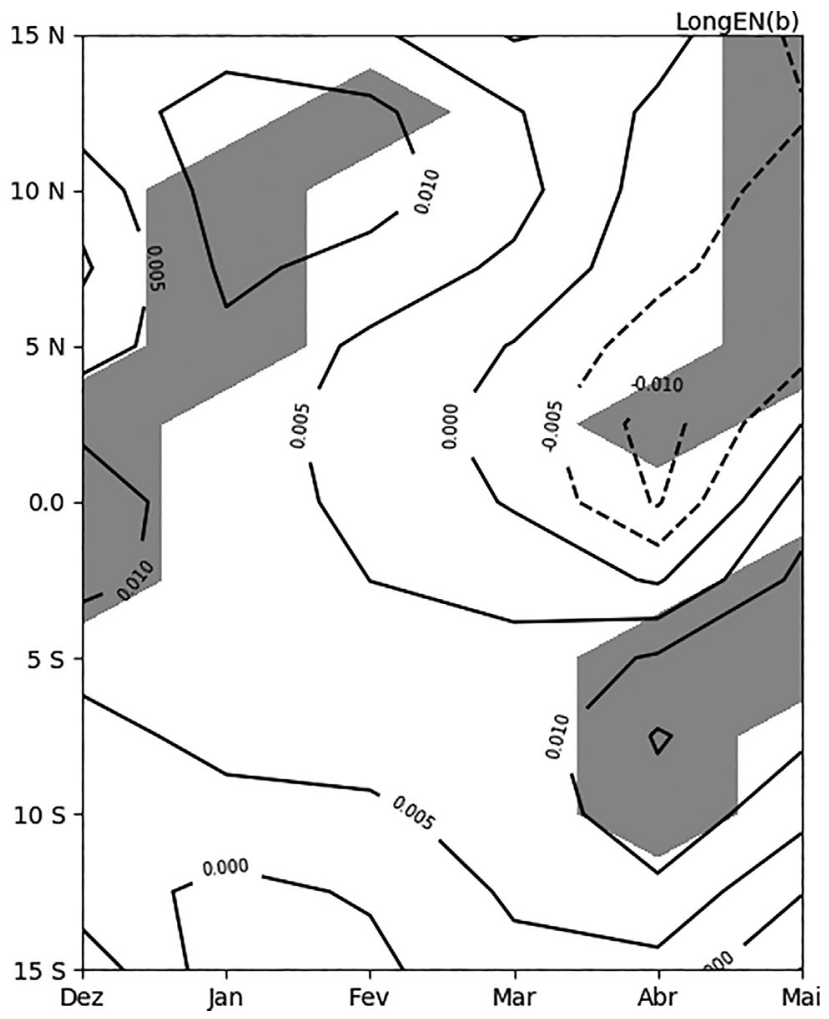

Figura 14 - Seção latitudinal (média entre $38^{\circ}-30^{\circ} \mathrm{O}$ ) da composição de ômega em $500 \mathrm{hPa}$ sobre Atlântico equatorial a) para anos de El Niño curto e b) anos de El Niño longo com o espaçamento das isolinhas de 5 × $10^{-3} \mathrm{~Pa} / \mathrm{s}$. Áreas em cinza são estatisticamente significantes ao nível de confiança de $95 \%$. 

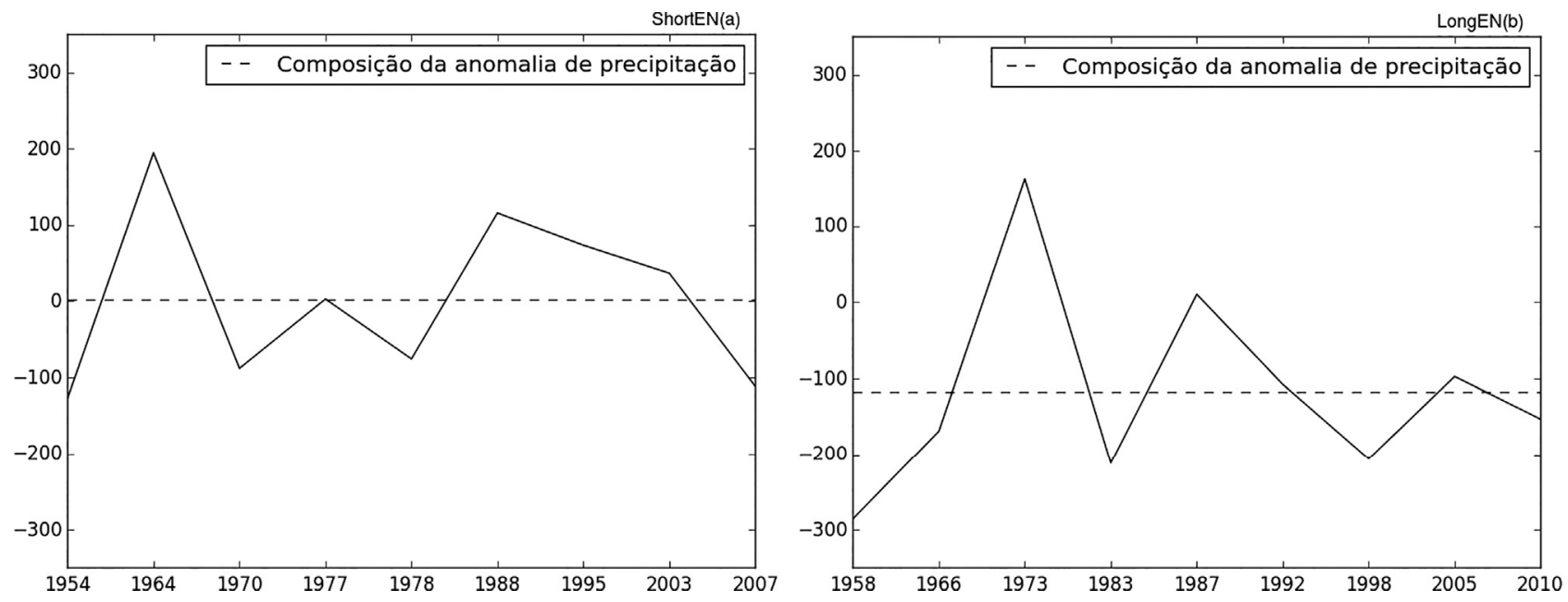

Figura 15 - Acumulado bimestral (Mar-Abr) das anomalias de precipitação sobre o Ceará em a) anos de El Niño curto e em b) anos de El Niño longo em $\mathrm{mm}$.
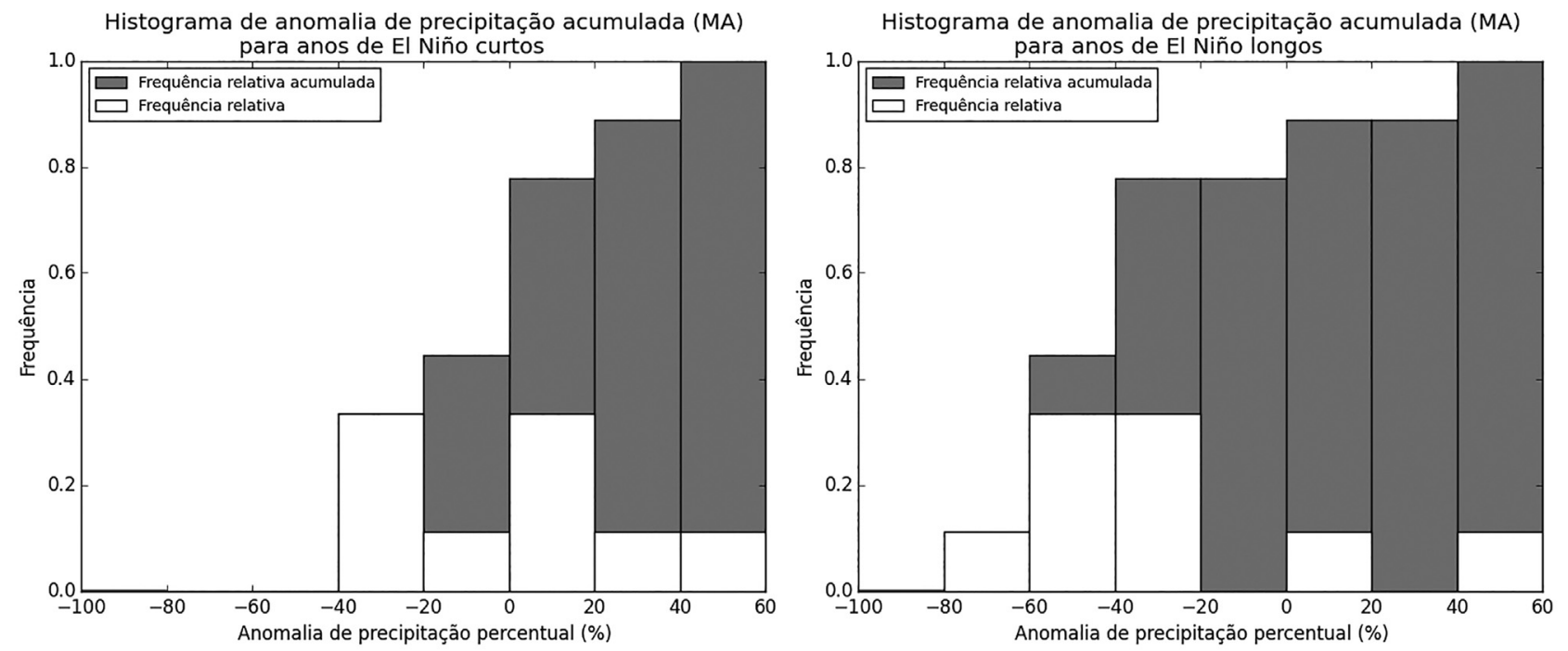

Figura 16 - Histograma da anomalia do acumulado de precipitação (MA) para a) anos de El Niño curto e b) anos de El Niño longo.

(1995), só é observado em anos no qual o fenômeno apresentou longa duração.

Essa cadeia de mecanismos é iniciada pelo trem de ondas entre o Pacífico equatorial e o Atlântico Norte. Associado a isso, padrões de divergência anômala diminuem a subsidência sobre a ASAN causando a redução da pressão superficial no ATN e provocando a formação de um gradiente norte-sul de pressão em superfície. Isso favorece os alísios do HS a cruzarem o equador e desacelerarem os alísios do $\mathrm{HN}$, reduzindo assim o WES feedback, e conduzindo a formação de um gradiente inter-hemisférico térmico, com anomalias de TSM maiores sobre a região do ATN.

Dos nove eventos de El Niño curto, seis deles resultaram em gradientes de anomalias de TSM negativos no Atlântico Tropical e três positivos. A média destes ficou próximo de $0.1^{\circ} \mathrm{C}$ durante a outono austral. Já em anos El Niño longo, oito dos nove eventos resultaram em gradientes de TSM positivos e um negativo, com a média próxima de $0.5^{\circ} \mathrm{C}$ durante o outono austral. As alterações na circulação de Hadley sobre o Atlântico, observadas na composição de ômega em $500 \mathrm{hPa}$, confirmam esses resultados, já que a composição dos eventos longos mostra movimentos ascendentes mais intensos sobre o ATN e menos intensos sobre o ATS, enquanto os eventos curtos fracas anomalias indicam pouca modificação da circulação meridional.

O gradiente de anomalias de TSM do Atlântico Tropical, por sua vez, controla a posição latitudinal da ZCIT, o qual é o principal responsável pelo regime de precipitação sobre o Ceará. Dos nove eventos de El Niño longo, sete ( $\sim 80 \%$ do total) deles resultaram em um regime de precipitação abaixo da média, e dois acima da média histórica do 
estado. Uma proporção diferente acontece para anos de El Niño curto, no qual, dos nove eventos, cinco deles resultaram em anomalias positivas e quatro em anomalias negativas de precipitação. A severidade dos eventos de seca também foi maior em anos de El Niño longo, chegando a alcançar anomalias até $80 \%$ menores do que a média histórica, enquanto nos anos de El Niño curto as anomalias de precipitação não passaram de $40 \%$ da climatologia. As composições das anomalias de precipitação acumulada para o bimestre MA foram aproximadamente $-110 \mathrm{~mm}$ e $0 \mathrm{~mm}$ respectivamente.

Baseado nesses resultados, é reiterado a importância da fonte de calor no Pacífico equatorial permanecer atuando até o início do outono austral para que a ponte atmosférica entre o Pacífico equatorial e o Atlântico Norte resulte em modificações na circulação atmosférica capazes de influenciar, de forma dominante, os processos termodinâmicos no ATN. Caso contrário, os modos de variabilidade interna do Atlântico, nos quais já foram investigadas em diversos estudos (Servain, 2003; Knight e Scaife, 2006; Grossmann e Klotzbach, 2009; Kayano e Capistrano, 2013), serão determinantes para o estabelecimento das condições oceânicas na região.

\section{Agradecimentos}

Os autores agradecem ao National Centers for Environmental Prediction (NCEP) pela disponibilização dos dados utilizados neste trabalho.

\section{Referências}

BJERKNES, J. Atmospheric Teleconnections from The Equatorial Pacific. Monthly Weather Review, v. 97, n. 3, p. $163-172,1969$.

CHANG, P.; JI, L.; LI, H. A decadal climate variation in the tropical Atlantic Ocean from thermodynamic air-sea interactions. Nature, v. 385, n. 6616, p. 516-518, 1997.

CHIANG, J.C.H.; SOBEL, A.H. Tropical tropospheric temperature variations caused by ENSO and their influence on the remote tropical climate. Journal of Climate, v. 15, n. 18, p. 2616-2631, 2002.

CURTIS, S.; HASTENRATH, S. Forcing of anomalous sea surface temperature evolution in the tropical Atlantic during Pacific warm events. Journal of Geophysical Research, v. 100, n. 8 , p. $15835,1995$.

ENFIEL, D.B.; MAYER, D.A. Tropical Atlantic sea surface temperature variability and its relation to El Nifio-Southern Oscillation. Journal of Geophysical Research, v. 102, n. 1, p. 929-945, 1997.

GROSSMANN, I.; KLOTZBACH, P.J. A review of North Atlantic modes of natural variability and their driving mechanisms. Journal of Geophysical Research Atmospheres, v. 114, n. 24, p. 1-14, 2009.

HASTENRATH, S. Interannual Variability and Annual Cycle: Mechanisms of Circulation and Climate in the Tropical Atlantic Sector. Monthly Weather Review, v. 112, n. 6, p. 1097-1107, 1984.
HASTENRATH, S.; HELLER, L. Dynamics of climatic hazards in northeast Brazil. Quarterly Journal of the Royal Meteorological Society, v. 103, n. 435, p. 77-92, 1977.

HASTENRATH, S.; MERLE, J. Annual Cycle of Subsurface Thermal Structure in the Tropical Atlantic Ocean. Journal of Physical Oceanography, v. 17, n. 9, p. 1518-1538, 1987.

HOREL, J.D.; WALLACE, J.M. Planetary-scale phenomena associated with the Southern Oscillation. Mon. Wea. Rev., v. 109, n. 10 , p. $813-829,1981$.

HOSKINS, B.J.; AMBRIZZI, T. Rossby Wave Propagation on a Realistic Longitudinally Varying Flow. Journal of the Atmospheric Sciences, v. 50, n. 12, p. 1661-1671, 1993.

HUANG, B.; THORNE, P.W.; BANZON, V.F.; BOYER, T.; CHEPURIN, G. et al. Extended reconstructed sea surface temperature version 4 (ERSST.v4). Part I: Upgrades and intercomparisons. Journal of Climate, v. 28, n. 3, p. 911930, 2015.

KALNAY, E.; KANAMITSU, M.; KISTLER, R.; COLLINS, W.; DEAVEN, D. et al. The NCEP/NCAR 40-year reanalysis project. Bulletin of the American Meteorological Society, v. 77, n. 3, p. 437-471, 1996.

KAROLY, D.J. Rossby wave propagation in a barotropic atmosphere. Dynamics of Atmospheres and Oceans, v. 7, n. 2, p. 111-125, 1983.

KAYANO, M.T.; CAPISTRANO, V.B. How the Atlantic multidecadal oscillation (AMO) modifies the ENSO influence on the South American rainfall. International Journal of Climatology, v. 34, n. 1, p. 162-178, 2014.

KNIGHT, J.R.; FOLLAND, C.K.; SCAIFE, A.A. Climate impacts of the Atlantic multidecadal oscillation. Geophysical Research Letters, v. 33, n. 17, 2006.

KUG, J.S.; FEI, F.J.; Soon, I.A. Two Types of El Niño Events: Cold Tongue El Niño and Warm Pool El Niño. Journal of Climate, v. 22, n. 6, p. 1499-1515, 2009.

LI, L.; NATHAN, T.R. The global atmospheric response to lowfrequency tropical forcing: Zonally averaged basic states. J. Atmos. Sci, v. 51, n. 23, p. 3412-3426, 1994.

MOURA, A.D.; SHUKLA, J. On the dynamics of droughts in Northeast Brazil: Observations, theory, and numerical experiments with a general circulation model. Journal of Atmospheric Sciences, v. 38, n. 12, p. 2653-2675, 1981.

LIU, W. et al. Extended reconstructed sea surface temperature version 4 (ERSST.v4): Part II. Parametric and structural uncertainty estimations. Journal of Climate, v. 28, n. 3, p. 931-951, 2015.

NOBRE, P.; SHUKLA, J. Variation of Sea surface Temperature, Wind Stress, and Rainfall over the Tropical Atlantic and South America. Journal of Climate, v. 9, n. 10, p. 2464-2479, 1996.

RASMUSSON, E.M.; KINGTSE MO. Linkages between 200-mb tropical and extratropical circulation anomalies during the 1986-1989 ENSO cycle. Journal of Climate, v. 6, n. 4, p. 595-616, 1993.

RODRIGUES, R.R.; HAARSMA, R.J.; CAMPOS, E.D.J.; AMBRIZZI, T. The impacts of inter-El Niño variability on the tropical Atlantic and northeast Brazil climate. Journal of Climate, v. 24, n. 13, p. 3402-3422, 2011.

SARDESHMUKH, P.D.; HOSKINS, B.J. The Generation of Global Rotational Flow by Steady Idealized Tropical Divergence. Journal of the Atmospheric Sciences, v. 45, n. 7, p. 1228-1251, 1988. 
SERVAIN, J. Modes of tropical Atlantic climate variability observed by PIRATA. Geophysical Research Letters, v. 30, n. 5, p. 1-4, 2003.

TRENBERTH, K.E. et al. Progress during TOGA in understanding and modeling global teleconnections associated with tropical sea surface temperatures. Journal of Geophysical Research-Oceans, v. 103, n. C7, p. 14291-14324, 1998.

TRENBERTH, K.E. The Definition of El Niño. Bulletin of the American Meteorological Society, v. 78, n. 12, p. 27712777, 1997.
WILKS, D.S. Statistical methods in the atmospheric sciences. 2nd ed. San Diego: Academic Press, v. 91, 2006.

ZEBIAK, S.E.; CANE, M. A. A model El Nino-Southern Oscillation. Monthly Weather Review, v. 115, n. 10, p. 22622278, 1987.

ZHENG, F.; FANG, X.H.; YU, J.Y.; ZHU, J. Asymmetry of the Bjerknes positive feedback between the two types of El Niño. Geophysical Research Letters, v. 41, n. 21, p. 76517657, 2014

This is an Open Access article distributed under the terms of the Creative Commons Attribution Non-Commercial License which permits unrestricted non-commercial use, distribution, and reproduction in any medium provided the original work is properly cited. 